\title{
$50 \mathrm{kHz}$ 체장어군탐지기용 분할 빔 음향 변환기의 지향성 보정 및 위치각 추정 \\ 이대재*
}

부경대학교 해양생산시스템관리학부

\section{Estimation of Angular Location and Directivity Compensation of Split-beam Acoustic Transducer for a $50 \mathrm{kHz}$ Fish Sizing Echo Sounder}

\author{
Dae-Jae Lee* \\ Division of Marine Production System Management, Pukyong National University, Busan 608-737, Korea
}

The most satisfactory split-beam transducer for fish sizing maintains a wide bearing angle region for correct fish tracking without interference from side lobes and lower sensitivity to fish echoes outside of the main lobe region to correctly measure the angular location of free-swimming fishes in the sound beam. To evaluate the performance of an experimentally developed $50 \mathrm{kHz}$ split-beam transducer, the angular location of a target was derived from the electrical phase difference between the resultant signals for the pair of transducer quadrants in the horizontal and vertical planes consisting of 32 transducer elements. The electrical phase difference was calculated by cross-spectral density analysis for the signals from the pair of receiving transducer quadrants, and the directivity correction factor for a developed split-beam transducer was estimated as the fourth-order polynomial of the off-axis beam angle for the angular location of the target. The experimental results demonstrate that the distance between the acoustic centers for the pair of receiving transducer quadrants can be controlled to less than one wavelength by optimization with amplitude-weighting transformers, and a smaller center spacing provides a range of greater angular location for tracking of a fish target. In particular, a side lobe level of $-25.2 \mathrm{~dB}$ and an intercenter spacing of $0.96 \lambda(\lambda$ $=$ wavelength) obtained in this study suggest that the angular location of fish targets distributing within a range of approximately $\pm 28^{\circ}$ without interference from side lobes can be measured.

Key words: Split beam transducer, Directivity compensation, Acoustic center spacing, Angular location estimation, Target strength

\begin{abstract}
서 론
체장어군탐지기는 음향 변환기로부터 발사되는 초음파 펄 스 신호의 송파 음압 레벨과 해중에 분포하는 어류로부터 산란 되는 echo 신호 레벨의 비, 즉 음향반사강도가 어류의 체장에 비례한다는 이론적 및 실험적 관계를 토대로 현장에서 측정한 반사강도 값을 어류의 체장으로 변환하여 지시하는 장비이다 (MacLeannan et al., 1995). 이 때, 현장에서 측정되는 반사강도 에 오차가 내포되면 그 오차에 비례하는 만큼 어류의 체장 추정 치에 오차가 발생하여 체장어군탐지기의 신뢰도에 큰 영향을 미 치게 된다. 현재 세계 여러 나라에서는 현장에서 직접 어류의 체 장에 관한 정보를 모니터링하기 위한 방법으로서 split beam 방 식 체장어군탐지기가 널리 사용되고 있다. 이와 같이 어류의 반 사강도를 측정하여 체장으로 변환할 때, 가장 중요한 요소 중의
\end{abstract}

*Corresponding author: daejael@pknu.ac.kr
하나는 음향 변환기에 대한 지향성 보정기술이다(Brede et al., 1987; Foote, 1990; Hood, 1987). 대부분의 음향 변환기로부터 방사되는 음향 에너지는 음축 방향으로는 가장 강하게 송출되 고, 음축으로부터 벗어날수록 점차 약해지는 지향특성을 갖는 다(Balanis, 1997; Quaji, 1982; Ziomeck, 1985). 따라서, 체장 어군탐지기에서는 어떤 동일한 어류가 음향 변환기의 유효 지 향각내의 어떤 위치에 존재하더라도 항상 같은 레벨의 echo 신 호를 발생시키기 위한 기술, 즉 지향성 보정기술이 도입되고 있 다(Lee et al., 2011). 이 때, split beam 음향 변환기의 지향성을 효과적으로 보정하기 위해서는 sidelobe 레벨을 적극 억제시켜 dynamic range를 증대시키고, 음향 변환기에서 송출되는 음향 펄스신호에 반응하여 수신되는 어류 echo 신호의 도래방향을 보 다 넓은 지향각 범위에 걸쳐 처리할 수 있어야 한다(Park et al., 2004).

본 연구에서는 저자들이 개발한 $50 \mathrm{kHz}$ split beam 음향 변 환기(Lee et al., 2011)를 대상으로 어류의 체장 추정 오차를 저 
감시키기 위한 목적의 일환으로 수신 지향성 빔에 대한 음향 중 심 간격의 추정, 어류의 위치각 추정기법의 검증, 위치각 범위와 sidelobe 레벨의 관계 등을 종합적으로 분석하여 지향성 보정 패 턴을 유도하고 평가, 분석하였다.

\section{재료 및 방법}

실험장치 구성
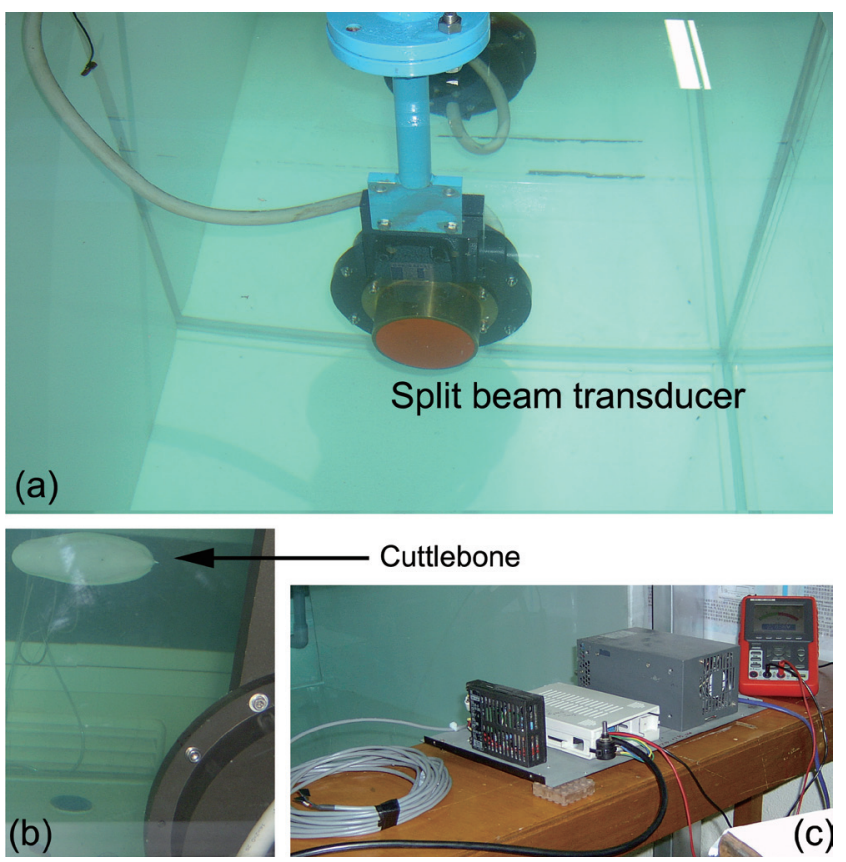

Fig. 1. Photographs showing a developed $50 \mathrm{kHz}$ split-beam transducer fixed horizontally in the acrylic water tank (a), the cuttlebone mounted horizontally at $1.5 \mathrm{~m}$ distance from transducer in the sound beam (b) and experimental setup for measuring the angular position of cuttlebone target (c).

본 연구에서는 저자들에 의해 개발된 $50 \mathrm{kHz}$ split beam 음향 변환기(Lee et al., 2011)를 대상으로 지향성 보정 및 수중 물표 의 위치각 추정을 위한 실험을 행하였는데, 그 실험 장치는 Fig. 1 과 같다. 또한, 음향 변환기의 빔 내에 분포하는 수중 물표의 위 치각을 검출하기 위한 4 분할 수신 진동자 블록의 모식도는 Fig. 2 와 같다. 특히, 여기서는 split beam 음향 변환기의 신뢰성을 검 증할 목적으로 갑오징어의 cuttlebone에 대한 반사강도를 측정 하고, 그 결과를 노르웨이 Simrad 사의 ES70 split beam echo sounder의 측정치와 비교하였다. 또한, 자체 제작한 $50 \mathrm{kHz}$ 수 중 transponder의 위치각을 추정하여 실제의 위치각과 비교, 분 석하였다. 실험은 투명아크릴수조 $(\mathrm{L} 1.2 \mathrm{~m} \times \mathrm{W} 1.2 \mathrm{~m} \times \mathrm{H} 1.7 \mathrm{~m})$ 내부에 Fig. 1(a)에서와 같이 조사대상 split beam 음향 변환기 를 설치하고, Fig. 1(b)에서와 같이 음향 빔 내의 약 $1.2 \mathrm{~m}$ 위치 에 각각 cuttlebone과 수중 transponder를 설치한 후, cuttlebone 에 대해서는 echo 신호를, 또한, 수중 transponder에 대해서는 직
접파 신호를 4 분할 수신 진동자 블록으로 각각 수신하여 $\mathrm{A} / \mathrm{D}$ 변 환한 후, 목적에 따른 분석을 수행하였다. cuttlebone의 반사강 도 측정 시에는 임의파형발생기(33120A, HP, USA)를 이용하 여 펄스폭 $0.5 \mathrm{~ms}$, 주파수 $50 \mathrm{kHz}$ 의 송신펄스신호를 발생시켜 전력증폭기(2713, B\&K, Denmark)를 통해 증폭한 후, 이 신호 를 matching network을 경유하여 조사대상 $50 \mathrm{kHz}$ split beam 음향 변환기에 인가하였다. Echo 신호는 Fig. 2의 DL, DR, UL 및 UR의 수신 진동자 블록을 통해 수신하고, 이 신호를 파형분 석기(HT-600, Hi-techniques, USA)에 입력하여 $2 \mathrm{MHz}$ 의 샘 플링 주파수로 정량화한 후, 위치각을 검출하였다. 한편, 수중 transponder로부터 송출되는 음향신호는 같은 방법으로 split beam 음향 변환기의 4 분할 진동자 블록으로 수신하여 $1 \mathrm{MHz}$ 의 샘플링주파수로 정량화하여 위치각을 검출하였다.

\section{위상검출}

Fig. 2에서 위치각은 먼저 split beam 음향 변환기의 4 분할 진동자 블록 $\mathrm{UL}, \mathrm{UR}, \mathrm{DL}, \mathrm{DR}$ 에 도래하는 각각의 echo 신호를 수신하여 UL+UR과 $\mathrm{DL}+\mathrm{DR}$, 또한 $\mathrm{UL}+\mathrm{DL}$ 과 $\mathrm{UR}+\mathrm{DR}$ 블록에 대한 합성 echo 신호를 각각 구한 후, $\mathrm{UL}+\mathrm{UR}$ 과 $\mathrm{DL}+\mathrm{DR}$ 의 진 동자 블록으로부터 각각 출력되는 두 echo 신호의 위상각을 구 해 수직방향 $\left(0^{\circ} \mathrm{plane}\right)$ 에 대한 물표의 위치각을 산출하였다. 같 은 방법으로 $\mathrm{UL}+\mathrm{DL}$ 과 $\mathrm{UR}+\mathrm{DR}$ 의 진동자 블록으로부터 각각 출 력되는 두 echo신호의 위상각을 구해 수평방향 $\left(90^{\circ}\right.$ plane $)$ 에 대 한 물표의 위치각을 산출하였다. 즉, 수평방향의 경우, $\mathrm{UL}+\mathrm{DL}$ 블록으로부터 출력되는 echo 신호를 $x(t), \mathrm{UR}+\mathrm{DR}$ 블록으로부 터 출력되는 echo 신호를 $y(t)$, 또한, $x(t)$ 에 대한 $y(t)$ 의 수신시간 의 지연을 $\tau$ 라 할 때, 이들 두 echo 신호의 상호 상관함수(cross correlation function) $r_{x y}(\tau)$ 를 시간지연 $\tau$ 에 대하여 나타내면

$$
r_{x y}(\tau)=<x(t) y(t-\tau)>=\int_{-\infty}^{\infty} x(t) y(t-\tau) d t
$$

이 되고, 이 상호상관함수의 상호 스펙트럼 밀도함수(cross spectral density function) $R_{x y}(f)$ 는

$$
R_{x y}(f)=F\left[r_{x y}(\tau)\right]=\int_{-\infty}^{\infty} r_{x y}(\tau) e^{-j 2 \pi f \tau} d \tau
$$

이 된다. 여기서, $\mathrm{F}[*]$ 는 Fourier 변환을 의미하고, 수중물표로 부터 산란된 echo 신호 $x(t)$ 와 $y(t)$ 의 위상각은 split beam 음향 변환기의 주파수에 대한 $R_{x y}(f)$ 로부터 산출되는 상대위상 스펙 트럼(relative phase spectrum)의 값으로부터 구할 수 있다. 이를 위해 먼저 $x(t)$ 와 $y(t)$ 신호를 $\mathrm{A} / \mathrm{D}$ 변환한 후, 이들 수치화된 이 산신호 $X(n), y(n)$ 에 대한 상호 상관함수 $r_{x y}(m)$ 을 나타내면

$$
r_{x y}(m)=E[x(m) y(n-m)]=\sum_{n=0}^{N-1} x(n) y(n-m)
$$

이 되고, 여기서, $m$ 은 $x(n)$ 이 $y(n-m)$ 과 얼마나 어긋나 있는가를 샘플링 point로 나타낸 수이므로, 만약 $m$ 에 샘플링 간격 $(\Delta t)$ 을 


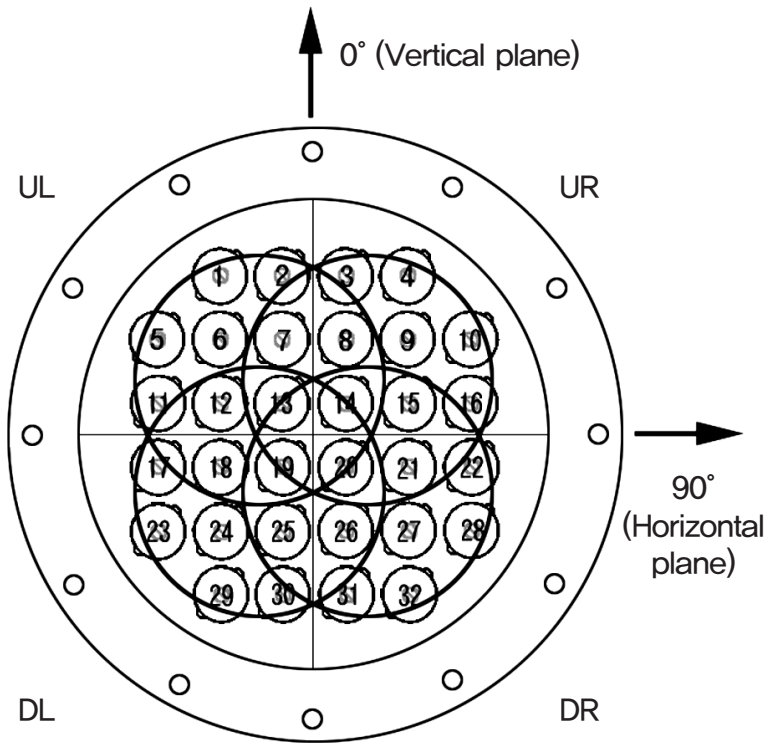

Fig. 2. A drawing showing the four receiving transducer quadrants in the geometrical arrangement of transducer elements with the distance between acoustic centers of less than one wavelength for each axis and the inter-element spacing of 0.5 wavelength for a $50 \mathrm{kHz}$ split-beam transducer.

곱하면 두 echo 신호의 수신 시간차를 구할 수 있다. 한편, 이산 신호 $x(n), y(n)$ 에 대한 상호 스펙트럼 밀도함수 $R_{x y}(k)$ 는

$$
\begin{aligned}
R_{x y}(k) & =F\left[r_{x y}(m)\right]=\sum_{m=0}^{N-1} r_{x y}(m) e^{-j 2 \pi \frac{k m}{N}} \\
& =\sum_{m=0}^{N-1}\left(\sum_{n=0}^{N-1} x(n) y(n-m)\right) e^{-j 2 \pi \frac{k m}{N}} \\
& =\sum_{n=0}^{N-1} x(n) e^{j 2 \pi \frac{k n}{N}} \cdot\left(\sum_{m=0}^{N-1} y(n-m) e^{j 2 \pi \frac{k(n-m)}{N}}\right) \\
& =X(k) Y^{*}(k)=C_{x y}(k)-j Q_{x y}(k)
\end{aligned}
$$

에 의해 구할 수 있다. 여기서, $F[*]$ 는 Fourier 변환을 의미하 고, * 는 복소공액(complex conjugate)이며, $X(k), Y(k)$ 는 $X(t)$ 와 $y(t)$ 의 Fourier 변환이다. 또한, 상호 스펙트럼 밀도의 실수 부 $C_{x y}(k)$ 와 허수부 $Q_{x y}(k)$ 는 각각 co-spectrum, quadrature spectrum으로서, $R_{x y}(k)$ 는

$$
\begin{aligned}
& R_{x y}(k)=\left|R_{x y}(k)\right| e^{j \theta_{x y}(k)} \\
& \left|R_{x y}(k)\right|=\sqrt{C_{x y}^{2}(k)+Q_{x y}^{2}(k)} \\
& \theta_{x y}(k)=\tan ^{-1}\left(\frac{-Q_{x y}(k)}{C_{x y}(k)}\right)
\end{aligned}
$$

에 의해 정의된다(Hans et al., 2001; Malcolm, 1998; Martyna, 2010). 이 식에서 $\theta_{x y}(k)$ 는 상대위상 스펙트럼(위상각)으로서 [ $\pi / 2,-\pi / 2$ ]의 범위에 분포하고, 먼저 $x(t)$ 와 $y(t)$ 의 두 echo 신호의 주파수에 따른 위상차(frequency dependent phase difference) 정보를 내포하고 있으므로 split beam 음향 변환기 의 주파수에 해당하는 샘플링 point $k$ 에 대한 $\theta_{x y}(k)$ 값을 구하 면 수중 물표가 존재하는 위치각을 구할 수 있다. 이 때, $\theta_{x y}(k)$ 가 양의 값을 갖는 경우에는 먼저 $x(t)$ 가 $y(t)$ 보다 먼저 수신된 경우 이고, 음의 값은 그 반대의 경우에 해당된다. 따라서, 이들 수직 및 수평 방향에 대한 위치각을 토대로 합성 위치각을 구하면 수 중물표가 존재하는 좌표를 구할 수 있고, 또한, 이 위치각에 대 한 지향성을 보정하여 반사강도를 추정할 수 있다.

\section{음향중심좌표 추출}

본 연구에서는 Fig. 2에서 split beam 음향 변환기의 UL+UR 과 $\mathrm{DL}+\mathrm{DR}$, 또한 $\mathrm{UL}+\mathrm{DL}$ 과 $\mathrm{UR}+\mathrm{DR}$ 블록에 대한 각각의 음향 중심좌표를 추출하기 위해 먼저 각 진동소자의 직각좌표 $s(i, j)$ 와 각 진동소자에 부여된 전압 가중치를 고려하여 음향중심좌표 $X_{C}, Y_{C}$ 를 추출하였다.

$$
\begin{aligned}
X_{c} & =\frac{\sum_{i=1}^{n} \sum_{j=1}^{m} z_{i}(j) s(i, j)}{\sum_{\mathrm{i}=1}^{\mathrm{n}} \sum_{\mathrm{j}=1}^{\mathrm{m}} s(i, j)} \\
Y_{c} & =\frac{\sum_{i=1}^{n} \sum_{j=1}^{m} z_{j}(i) s(i, j)}{\sum_{i=1}^{n} \sum_{j=1}^{m} s(i, j)}
\end{aligned}
$$

여기서, $Z_{i}(j)$ 은 $X$ 축 방향의 $i$ 번째 진동소자 열에 대한 $j$ 번째 진동소자의 $y$ 좌표, $Z_{j}(i)$ 는 $y$ 축 방향의 $j$ 번째 진동소자 열에 대 한 $i$ 번째 진동소자의 $x$ 좌표, $s(i, j)$ 는 $i$ 번째 진동소자 열에 대한 $j$ 번째 진동소자의 전압 가중치, $n$ 과 $m$ 은 각각 $x$ 축과 $y$ 축 방향 에 대한 진동소자의 수이다.

\section{위치각 추정과 지향성 보정}

어류가 Fig. 2와 같이 배열된 split beam 음향 변환기의 음속 축(beam axis)에 대하여 $\theta_{L}$ 만큼 벗어난 방향에 위치하고 있을 때, 수직방향에 대한 수중물표의 위치각을 $\theta_{1}$, echo 신호의 전기 적인 위상차를 $\Delta \theta_{e}$, 수중음속을 $C$, 사용 주파수 $f$ 에 대한 수중 파장을 $\lambda(C=\lambda f, \omega=2 \pi f)$, 수신 진동자 그룹의 음향학적 중심 거리를 $d$ 라 하면,

$$
\theta_{1}=\sin ^{-1}\left(\frac{\Delta \theta_{\mathrm{e}} C}{\omega d}\right)
$$

에 의해 구할 수 있다. 여기서, 만일 $\left(\frac{\Delta \theta_{\mathrm{e}} C}{\omega d}\right)$ 의 값이 미소하다면

$$
\theta_{1} \approx \frac{\Delta \theta_{\mathrm{e}} C}{\omega d}=\frac{\lambda}{2 \pi \mathrm{d}} \cdot \Delta \theta_{\mathrm{e}}
$$

이 된다(Lee, 1999). 또한, 수평방향에 대해서도 동일한 방법으 로 echo 신호의 전기적인 위상각을 측정하면 수중물표의 위치 
각을 구할 수 있다. 이렇게 구한 수직 및 수평 방향에 대한 위치 각을 각각 $\theta_{1}, \theta_{2}$ 라 할 때, 음속 축에 대한 수중물표의 합성적인 위치각 $\theta_{L}$ 는

$$
\theta_{L}=\sin ^{-1}\left(\sqrt{\sin ^{2} \theta_{1}+\sin ^{2} \theta_{2}}\right)
$$

에 의해 구할 수 있다. 따라서, 이 위치각 $\theta_{L}$ 로부터 어류의 반사 강도(target strength, 이하 TS라 한다.)는

$$
T S=E L-(S L+V R+S G)-B_{\theta}
$$

에 의해 구할 수 있다(Lee, 1999). 여기서, $E L$ 은 echo level, 은 송파기의 source level, $V R$ 은 수파기의 수파감도, $S G$ 는 어탐 시 스템의 수신이득, $B_{\theta}$ 는 수중물표의 위치각에 대한 지향성 보정 치로서, $B_{\theta}=10 \log \left|b^{2}(\theta)\right|$ 이며, $b(\theta)$ 는 split beam 음향 변환 기의 지향성 패턴 함수이다.

본 연구에서는 저자들이 자체적으로 설계, 개발한 split beam 음향 변환기에 대한 지향성 보정함수를 유도하고, 이들 함수를 사용하여 탐지물표의 지향성 보정을 행하는 방법으로 음향 변 환기의 신뢰성을 검증하였다. 일반적으로 어로현장에서는 가능 한 한 보다 광범위한 범위에 분포하는 어류를 탐색하고자 하는 경우가 많다. 이를 실현하기 위해서는 split beam 음향 변환기의 sidelobe를 억제시켜 dynamic range를 증대시키고, 수신 진동자 블록 사이의 음향학적 중심 거리를 최소화시킬 필요가 있는데, 여기서는 이들 문제에 대해서도 정량적인 분석을 수행하였다.

\section{결과 및 고찰}

\section{음향 중심 간격과 유효 위치각 범위의 관계}

split beam 어군탐지기를 이용하여 해중에 분포하는 어류의 체장을 추정할 때, 어류가 존재하는 방향에 대한 지향성을 보정 하면 반사강도를 구할 수 있다. 이 때, 사용하고 있는 음향 변환 기의 선수 및 선미, 또한, 좌현과 우현 방향에 대한 한 쌍의 수신 진동자 블록으로부터 각각 수신되는 어류 echo 신호에 대한 전 기적인 위상각을 구해야 하는데, 그 전기적인 위상각은 이들 진 동자 블록에 대한 음향학적 중심 사이의 간격에 따라 주기적으 로 변동한다. 이와 같은 문제를 정량적으로 분석하기 위하여 50 $\mathrm{kHz}$ split beam 음향 변환기를 대상으로 수신 진동자 블록 사이 의 음향학적 중심 사이의 간격 $(d)$ 을 사용 파장 $(\lambda)$ 의 0.5 배, 1.0 배, 2.0 배, 3.0 배로 변화시켰을 때, 전기적인 위상각(electrical phase difference)과 기계적인 위상각(mechanical angle) 사이의 관계를 나타낸 결과는 Fig. 3 과 같고, 또한, $d / \lambda$ 와 기계적인 위 상각(어류의 위치각) 사이의 관계를 나타낸 결과는 Fig. 4와 같 다.

$\mathrm{Fig}, 3$ 에서 알 수 있는 바와 같이 선수와 선미, 또한 좌현과 우현에 대한 한 쌍의 수신 진동자 블록으로부터 각각 수신되는 echo 신호의 전기적인 위상각은 기계적인 위상각이 $-\pi / 2$ 부터

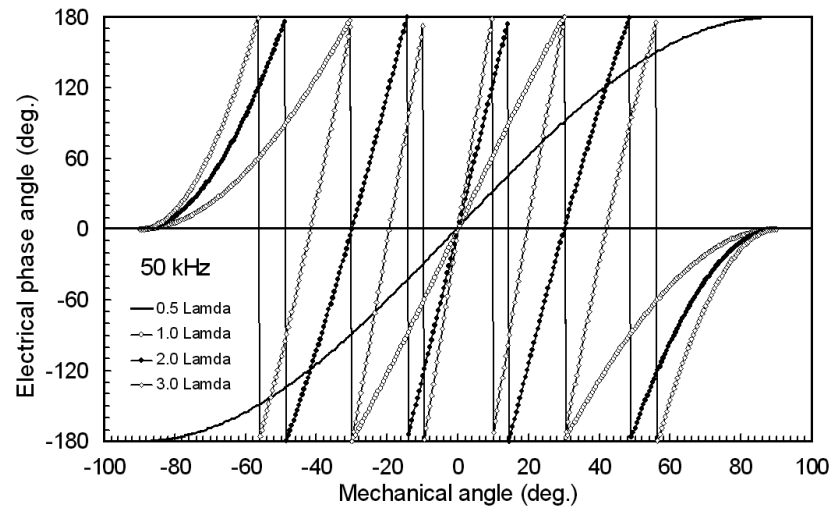

Fig. 3. Relationship between electrical phase angle and mechanical angle of underwater target to be detected in the sound beam with a varying spacing between acoustic centers for the pair of transducer quadrants of split beam transducer.

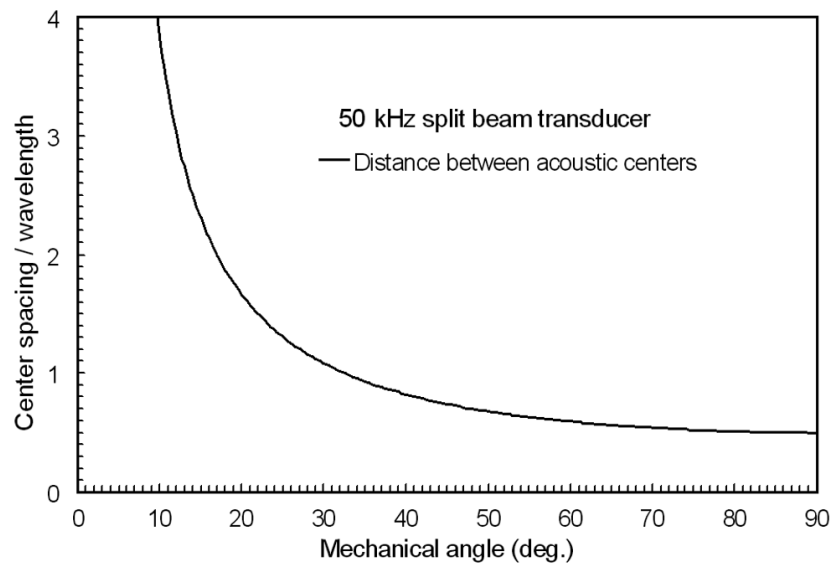

Fig. 4. Relationship between the angular bearing of target and the inter-center spacing between the pair of transducer quadrants $(d) /$ wavelength $(\lambda)$ for a $50 \mathrm{kHz}$ split-beam transducer.

$\pi / 2$ 까지 변화할 때, $-\pi$ 부터 $\pi$ 까지의 구간을 주기적으로 변화 하고 있다. 이 때문에 측정된 전기적인 위상각으로부터 어류의 위치각을 구하고자 할 때, 음향 빔 내에서 여러 개의 위치각이 동시에 나타나는 불확정성(uncertainty)이 발생한다. 따라서, 현 장에서 측정되는 어류 echo 신호의 선수미 및 정횡 방향에 대한 전기적인 위상각 정보로부터 어류의 위치각을 정확하게 추정하 기 위해서는 먼저 음축의 전후, 또는 좌우 방향에 대한 유효 위 치각 범위를 파악한 후, 측정된 어류의 위치각이 유효 위치각 범 위 내에서 존재하는 값인가를 판별해야 한다. 이를 위해 Fig. 3 에서는 음축의 전후, 또는 좌우 방향에 대한 유효 위치각 범위와 한 쌍의 분할 진동자 블록의 음향학적 중심 사이의 간격과 수중 파장의 비 $(d / \lambda)$ 와의 관계를 고찰 하였다. Fig. 4 에서 알 수 있는 바와 같이 $d / \lambda$ 가 $0.5,1.0,2.0,3.0$ 으로 변화 할 때, 어류의 유효 위치각 범위는 $90^{\circ}, 30^{\circ}, 14.5^{\circ}, 9.6^{\circ}$ 로 감소함을 알 수 있다. 본 연구에서 조사 대상으로 한 $50 \mathrm{kHz}$ split beam 음향 변환기의 경우, 수신 진동자 블록의 음향학적 중심 거리는 $d / \lambda=0.96$ 이 
고, 이 $d / \lambda$ 값에 대한 이론적인 유효 위치각 범위는 Fig. 4에서 $31.4^{\circ}$ 임을 알 수 있었다.

\section{유효 위치각 범위에 대한 sidelobe의 영향}

Fig. 3과 Fig. 4에서 얻은 이론적인 유효 위치각 범위가 실제 의 split beam 음향 변환기에 적용될 수 있는가를 파악하기 위해 서는 해당 음향 변환기의 수평 및 수직 지향성 패턴과 서로 연관 시켜 검토되어야 한다. 이를 위해 본 연구에서는 설계 목표치로 설정한 수신 진동자 블록의 음향 중심 간격 $d / \lambda=1.0$ 에 대한 전 기적인 위상각과 기계적인 위상각의 관계를 바탕으로 조사 대상 음향 변환기의 이용 가능한 위치각 범위를 추정한 결과는 Fig. 5와 같다. Fig. 5에서는 특히, sidelobe의 영향을 분석하기 위해 $6 \times 6$ 평면 배열 패턴에서 사각의 네모서리에 위치하는 초음파 소자를 하나씩 제거한 총 32개의 tonpilz형 진동소자 (Lee et al., 2010)를 $\lambda / 2$ 간격으로 평면 배열한 split beam 음향 변환기에 Dolph-Chebyshev 가중회로를 장착한 경우와 장착하지 않는 경 우에 대해 그 이론적인 지향성 패턴을 함께 중첩시켜 나타내었 다. Fig. 5에서 알 수 있는 바와 같이 가중회로가 장착되지 않은 경우에 있어서는 sidelobe의 출현 방향과 레벨이 각각 $\pm 30^{\circ}$, $-16 \mathrm{~dB}$ 이다.

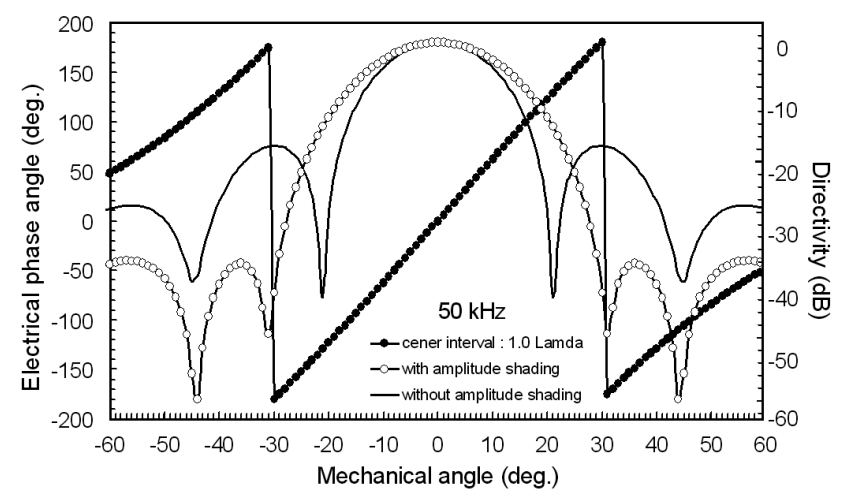

Fig. 5. Effect of the side lobe level in the directivity pattern influencing the range of angular bearing for correct target tracking without the positional ambiguity. The range of angular bearing increases with decreased level of side lobes.

일반적으로 split beam 어군탐지기에 있어서는 mainlobe의 지 향각 범위내에 분포하는 어류만을 대상으로 지향성 보정을 행하 여 반사강도를 측정하게 되므로 sidelobe의 영역에 분포하는 어류 에 대한 echo 신호는 식별하여 제거되어야 된다. Fig. 5에서 만일 어류가 sidelobe의 $\pm 30^{\circ}$ 의 방향과 main lobe의 $\pm 17.5^{\circ}$ 의 방 향에 동시에 존재할 때, 이들 두 방향으로부터 echo 신호가 함 께 수신되어 식별이 불가능하다. 이 때문에 sidelobe의 영향을 받지 않고 어류의 반사강도를 측정할 수 있는 유효 위치각 범위 는 $\pm 17.5^{\circ}$ 범위 내로 국한되는 문제가 발생한다. 그러나, Fig. 5 에서 가중회로가 장착된 경우에 있어서는 sidelobe의 출현 방향 과 레벨이 각각 $\pm 36^{\circ},-34.3 \mathrm{~B}$ 로서, sidelobe의 영향을 받지 않 고 mainlobe의 지향각 범위 내에서 어류의 반사강도를 측정할
수 있는 유효 위치각 범위는 $\pm 29.5^{\circ}$ 로 확대된다. 즉, 이 값은 가 중회로가 장착되지 않은 경우보다 $\pm 12^{\circ}$ 더 넓은 공간에 분포하 는 어류를 탐지할 수 있다는 것을 의미하고, 이로부터 어류의 체 장을 추정할 수 있는 위치각 범위는 sidelobe에 의해 결정되고 있음을 알 수 있다. 그러나, 여기서, sidelobe 레벨이 충분하게 억 제되어 탐지 dynamic range가 넓게 확보되어 있다 하더라도 두 분할된 진동자 블록의 음향중심 사이의 간격이 넓으면 넓을수 록 mainlobe의 지향성 패턴 내에서도 전기적인 위상각에 대응 하는 기계적인 위상각이 여러 개 존재하는 문제가 발생하기 때 문에 sidelobe를 억제 시킨 효과가 나타나지 않는다. 따라서, 두 분할된 진동자 블록의 음향학적 중심 사이의 간격에 의해 결정 되는 전기-기계 위상각 곡선(직선)과 sidelobe 레벨에 의해 결 정되는 위치각 범위의 관계를 평가, 분석하여 유효 위치각 범위 가 mainlobe 내부에서 결정되도록 수신 진동자 블록의 음향학 적 중심 사이의 간격을 설정하는 것이 중요하다. 본 연구에서 조 사대상으로 한 음향 변환기의 경우, 수신 진동자 블록의 음향학 적 중심 사이의 간격을 $d / \lambda=1.0$ 으로 하여 설계하였으나, 실제 의 측정된 결과는 $d / \lambda=0.96$ 이었다. 이 split beam 음향 변환기 를 대상으로 어류의 반사강도를 측정할 수 있는 유효 위치각 범 위를 추정하기 위해 측정 지향성 패턴과 $d / \lambda=0.96$ 에 대한 전기 적인 위상각과 기계적인 위치각의 관계를 함께 중첩시켜 나타내 는 결과는 Fig. 6과 같다. Fig. 6에서 측정 지향성 패턴은 수평방 향에 대한 지향성패턴으로 sidelobe의 출현 방향과 레벨은 각각 $37^{\circ},-24.7 \mathrm{~dB}$ 및 $-36^{\circ},-27.2 \mathrm{~dB}$ 이었다. 여기서 sidelobe의 레벨 이 높은 $-27.2 \mathrm{~dB}$ 을 기준으로 유효 위치각 범위를 산출한 결과, 그 값은 $-27^{\circ}-+29^{\circ}$ 범위이었다.. 즉, 조사 대상 split beam 음향 변환기는 음축을 중심으로 좌현측으로 $27^{\circ}$, 또한 우현측으로 $29^{\circ}$ 까지의 범위 내에 분포하는 어류에 대해서만 반사강도의 측 정이 가능함을 알 수 있었다.

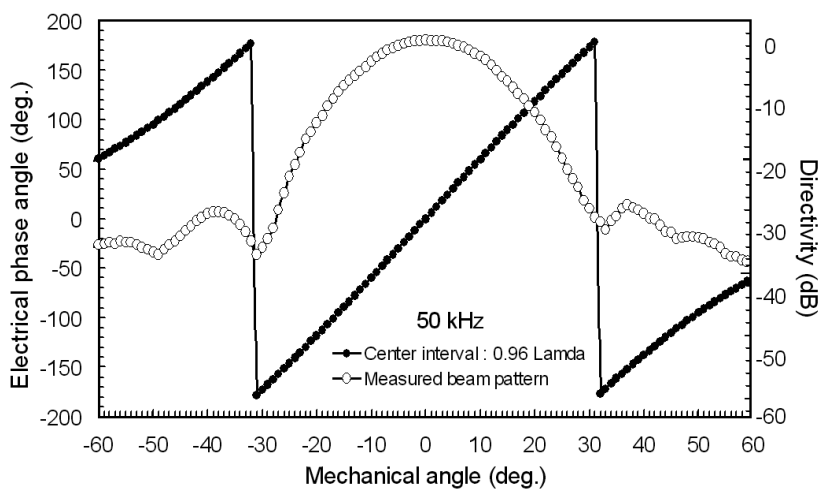

Fig. 6. The angular bearing limit usable in measuring the angular position without the positional ambiguity of target for a $50 \mathrm{kHz}$ split beam transducer with the inter-center spacing of 0.96 wavelength developed in this study.

\section{위치각의 검출과 지향성 보정}

본 연구에서는 Fig. 6의 mainlobe 내에 위치하는 수중물표 에 대한 위치각의 측정 정도를 검증할 목적으로 갑오징어의 

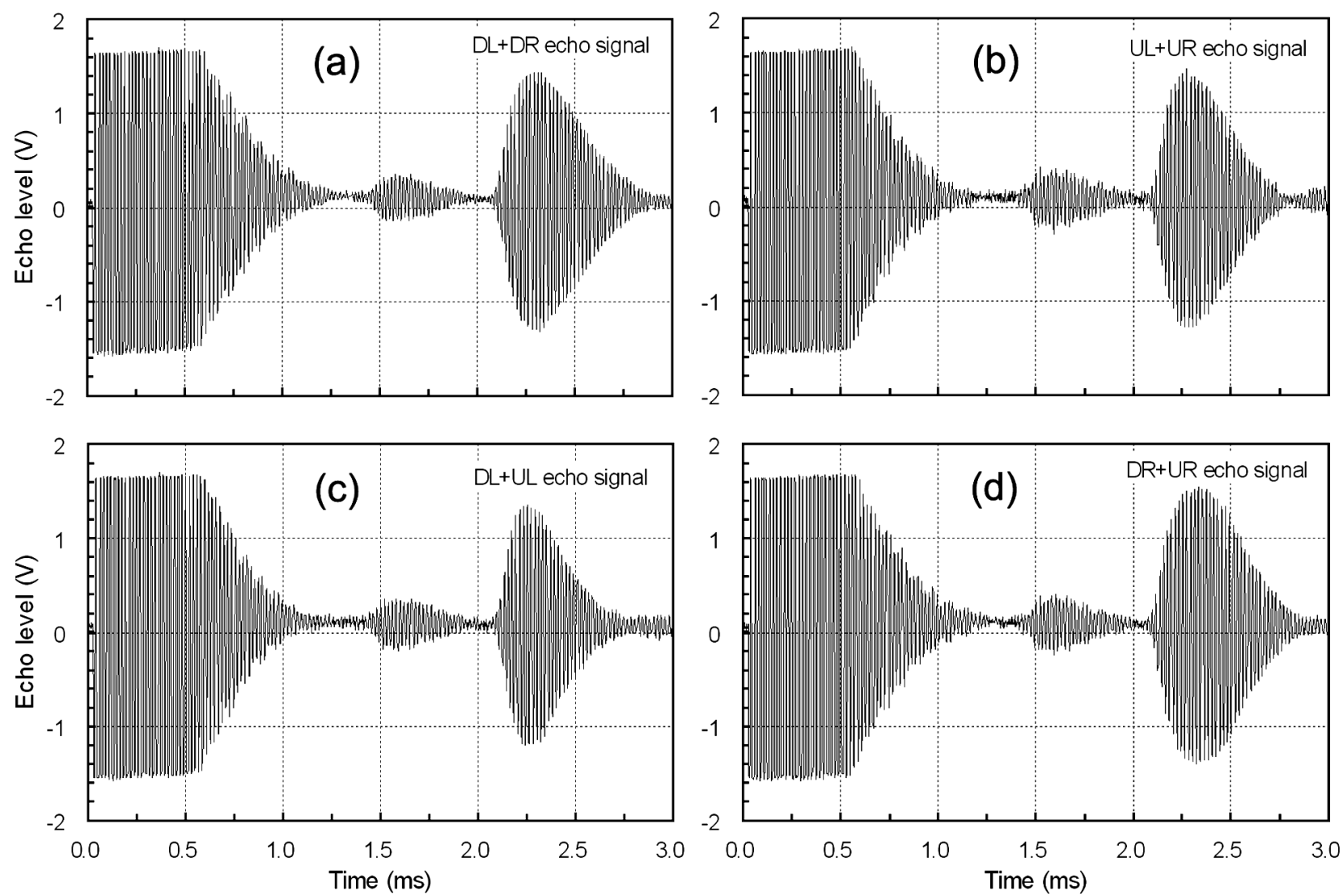

Fig. 7. Echo signals from a cuttlebone target received by the four pairs of the transducer quadrant blocks of split-beam transducer. (a) Echo signal from quadrants DL plus DR, (b) Echo signal from quadrants UL plus UR, (c) Echo signal from quadrants DL plus UL, (b) Echo signal from quadrants DR plus UR.

cuttlebone을 수중물표로 선정하여 위치각의 검출 실험을 행하 고, 그 위치각에 대한 지향성 보정을 행하여 반사강도를 추정하 였다.

특히, 이와 같이 측정된 반사강도의 신뢰도를 평가하기 위해 ES70 split beam echo sounder에 의한 측정 결과와도 비교, 분 석하였다. 실험은 Fig. 1에서와 같이 cuttlebone을 split beam 음 향 변환기의 음축으로부터 수직방향으로 약 $5^{\circ}$, 수평방향으로 $0^{\circ}$, 거리 약 $1.2 \mathrm{~m}$ 위치에 cuttlebone의 등쪽이 음향 변환기의 진동면을 향하도록 설치하고, 주파수 $50 \mathrm{kHz}$, 펄스폭 $0.5 \mathrm{~ms}$ 의 펄스신호를 송신하였다. cuttlebone으로부터 수신된 DL, DR, $\mathrm{UL}$ 및 UR의 수신 진동자 블록에 대한 echo 신호는 $2 \mathrm{MHz}$ 의 샘플링 주파수 $(\Delta t=0.5 \mu s)$ 로 정량화하여 수직방향에 대해서 는 $\mathrm{UL}+\mathrm{UR}$ 과 $\mathrm{DL}+\mathrm{DR}$ 의 수신 진동자 블록, 수평방향에 대해서 는 $\mathrm{UL}+\mathrm{DL}$ 과 $\mathrm{UR}+\mathrm{DR}$ 의 수신 진동자 블록에 대하여 얻어진 합 성 echo 신호를 대상으로 상호 스펙트럼 밀도 분석을 행하고, 이들 각 방향에 대한 위치각을 산출하였는데, 그 결과는 Fig. 7 과 같다. 또한, 반사강도 추정을 위하여 split beam 음향 변환기 의 수평 방향과 수직 방향에 대한 지향성 패턴의 측정치로부터 지향성 보정 곡선을 산출한 결과는 Fig. 8과 같다. Fig. 7의(a) 는 split beam 음향 변환기의 UL과 UR 블록으로부터의 출력
신호를 서로 합성하여 얻은 echo 신호로서 $1.0 \mathrm{~ms}$ 의 이전의 신 호는 송신펄스신호이고, $1.3 \mathrm{~ms}$ 와 $2.0 \mathrm{~ms}$ 사이에 출현하는 신 호는 cuttlebone에 의한 echo 신호, 또한 $2.1 \mathrm{~ms}$ 이후에 나타나 는 신호는 수조의 벽면에 의한 echo 신호이다. 한편, Fig. 7의(b) 는 DL과 DR 블록으로부터의 출력신호를 서로 합성하여 얻은 echo 신호, (c)는 DL과 UL 블록으로부터의 출력신호를 서로 합 성하여 얻은 echo 신호, (d)는 DR과 UR 블록으로부터의 출력신 호를 서로 합성하여 얻은 echo 신호이다. Fig. 7의 UL+UR블록 과 DL+DR 블록에 대한 echo 신호의 상호 스펙트럼 밀도의 cospectrum, quadrature spectrum으로부터 산출한 수직방향에 대 한 전기적인 위상각은 $27^{\circ}$ 이었고, 이 값에 대한 기계적인 위상 각, 즉, 음축에 대한 cuttlebone의 위치각은 약 $4.48^{\circ}$ 이었다. 한 편, $\mathrm{DL}+\mathrm{UL}$ 블록과 $\mathrm{DR}+\mathrm{UR}$ 블록에 대한 echo 신호의 상호 스펙 트럼 밀도의 co-spectrum, quadrature spectrum으로부터 산출 한 수평방향에 대한 전기 및 기계적인 위상각은 모두 $0^{\circ}$ 이었다. Fig. 7에서 검출된 수평방향에 대한 위치각은 실제의 위치각과 일치하였으나, 수직방향의 검출 위치각은 $0.52^{\circ}$ 의 오차를 나타 내었지만, 실용적으로 중요한 오차를 초래하는 수준은 아니라고 판단된다. 한편, Fig. 8의 split beam 음향 변환기에 대한 수직과 수평 방향에 대한 지향성 보정 패턴은(11)식, (12)식과 같이 최 
소자승법을 이용하여 4차 다항식 곡선으로 산출하였다.

$Y_{H}=-0.1347+0.04376 X-0.02542 X^{2}+0.00006276 X^{3}-0.00001006 X^{4}$

$Y_{V}=0.01832+0.02103 X-0.02865 X^{2}+0.00004677 X^{3}-0.00004234 X^{4}$

여기서, $Y_{H}, Y_{V}$ 는 각각 수평 및 수직 방향에 대한 지향성 보 정 곡선이고, $X$ 는 음축에 대한 위치각이다. 따라서, 이들 지향성 보정 곡선으로부터 cuttlebone의 수평 및 수직 방향의 위치각에 대한 지향성 보정치를 (13)식을 이용하여 구하면

$$
B_{\theta}=-\sqrt{Y_{H}^{2}+Y_{V}^{2}}
$$

$B_{\theta}=-0.48 \mathrm{~dB}$ 이 된다. 본 실험에 사용한 $50 \mathrm{kHz}$ split beam 음향 변환기에 대한 송파감도(transmitting voltage response, TVR)은 $161.5 \mathrm{~dB}$ re $1 \mu \mathrm{Pa} / V$ at $1 \mathrm{~m}$, 수파감도(receiving sensitivity, $\mathrm{VR})$ 는 $-178.0 \mathrm{~dB}$ re $1 \mathrm{~V} / \mu \mathrm{Pa}$ 이었고, 실험시 split beam 음향변기에 인가된 송신펄스신호의 전압은 $60 \mathrm{~V}$, 시스템 이득 $(S G)$ 은 $0 \mathrm{~dB}$, cuttlebone에 의한 echo 신호의 평균전압은 $0.38 \mathrm{~V}$ 이었다. 따라서, 실험에 사용한 cuttlebone의 반사강도는 (10)식에 의해 TS=-27.98 dB이 된다. 한편, 동일한 상황하에서 ES70 split beam echo sounder에 의한 측정한 cuttlebone의 반 사강도는 $-28.34 \mathrm{~dB}$ 로서 $0.36 \mathrm{~dB}$ 의 차이가 발생하고 있으나 이 차이는 실용적으로 체장 추정에 큰 영향이 없을 것으로 판단된다.
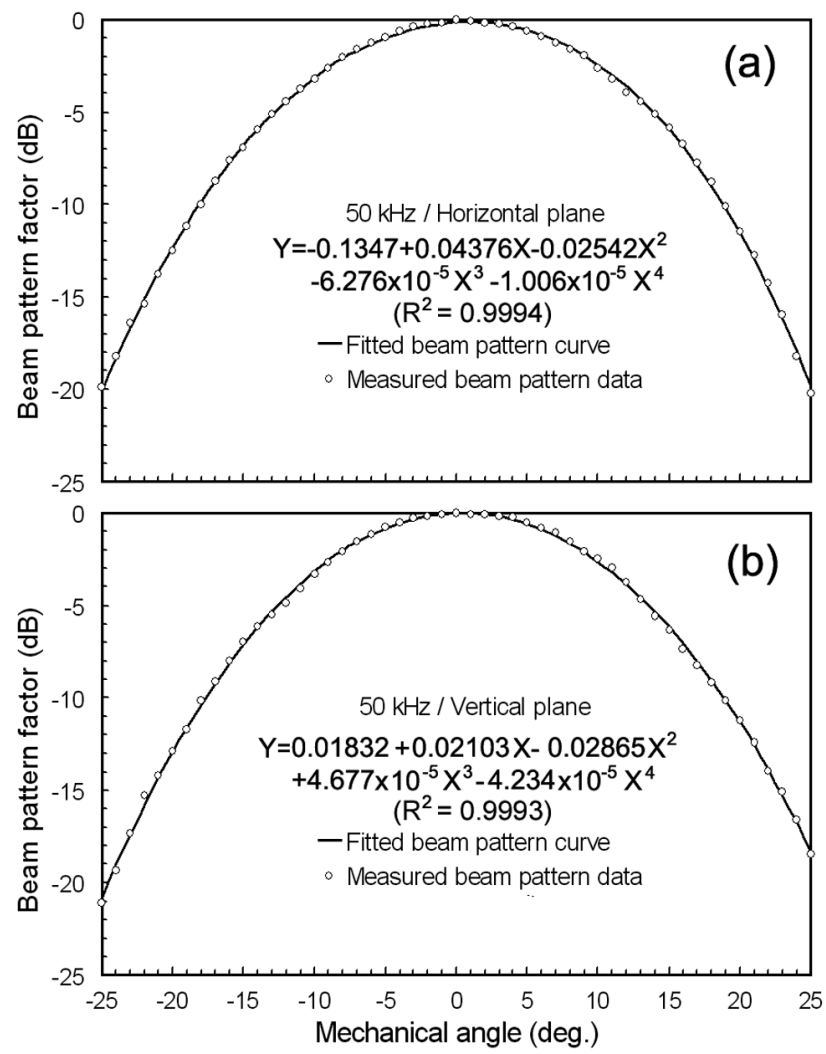

Fig. 8. Curves showing the directivity correction factor in the horizontal (a) and in the vertical planes (b) of a $50 \mathrm{kHz}$ splitbeam transducer.
한편, 본 실험에 사용한 $50 \mathrm{kHz}$ split beam 음향 변환기를 유 실 어구 추적용 수중 transponder의 위치 모니터링에 응용하기 위한 방안의 하나로서 수중 transponder로부터 발사되는 펄스 신호를 수신하여 transponder의 위치각을 추정한 결과는 Fig. 9 와 같다. Fig. 9는 수중 transponder를 split beam 음향 변환기의 음축으로부터 수직방향으로 $+10.3^{\circ}$, 수평방향으로 $+7.7^{\circ}$, 거리 약 $1.5 \mathrm{~m}$ 위치에 현수시키고, transponder에서 송신되는 주파수 $50 \mathrm{kHz}$, 펄스폭 $0.25 \mathrm{~ms}$ 의 gaussian 펄스신호를 모니터링한 결 과이다.
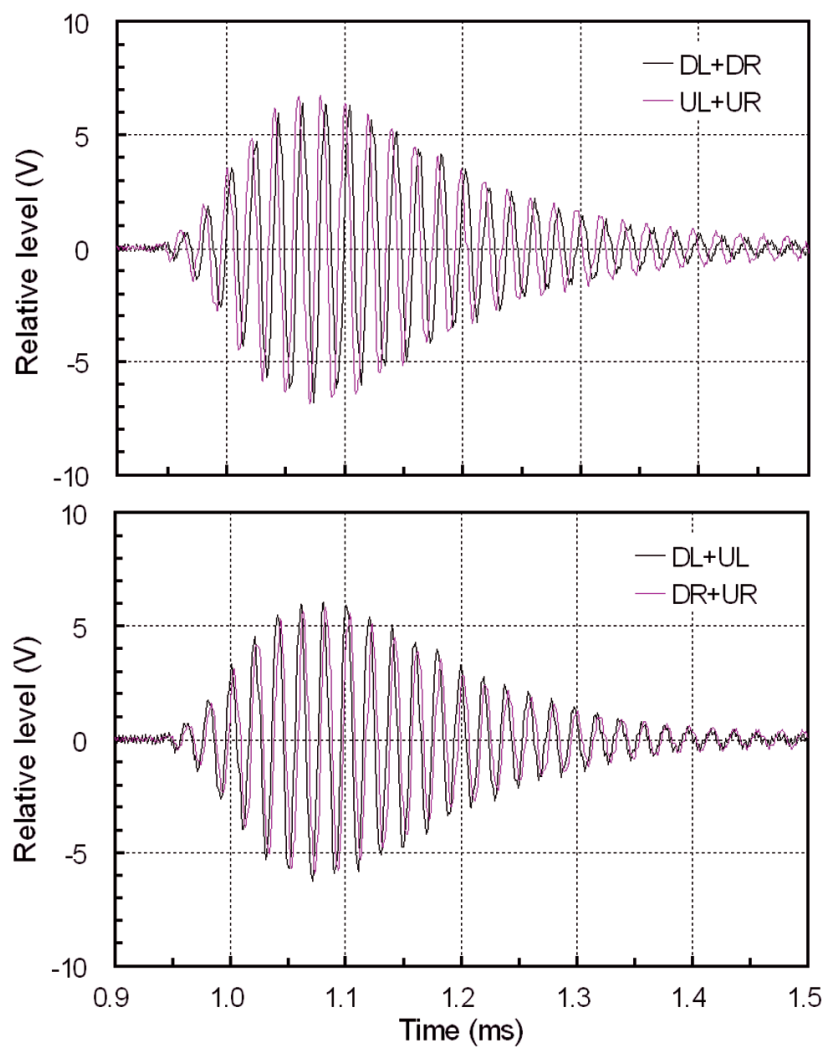

Fig. 9. Phase comparisons of $50 \mathrm{kHz}$ transponder signals received from the fore and aft halves in the vertical plane (a) and from the left and right halves in the horizontal plane (b) of split-beam transducer quadrants.

Fig. 9에서 split beam 음향 변환기의 DL, DR, UL 및 UR의 수신 진동자 블록으로부터 출력되는 직접파 신호는 $1 \mathrm{MHz}$ 의 샘플링 주파수 $(\Delta t=1.0 \mu \mathrm{s})$ 로 정량화하였고, 수직방향에 대해서 는 UL+UR과 DL+DR의 수신 진동자 블록, 또한, 수평방향에 대해서는 UL+DL과 UR+DR의 수신 진동자 블록에 대하여 합 성펄스신호를 구한 후, 이들 각 쌍의 펄스신호에 대한 상호 스펙 트럼 밀도 분석을 행하여 각 방향에 대한 위치각을 산출하였다. Fig. 9의 UL+UR블록과 DL+DR 블록에 대한 transponder 신호 의 상호 스펙트럼 밀도의 co-spectrum, quadrature spectrum으 로부터 산출한 수직방향에 대한 전기적인 위상각은 $65.9^{\circ}$ 이었 고, 이 값에 대한 기계적인 위상각, 즉, 음축에 대한 transponder 
의 위치각은 약 $10.6^{\circ}$ 이었다. 한편, $\mathrm{DL}+\mathrm{UL}$ 블록과 $\mathrm{DR}+\mathrm{UR}$ 블록에 대한 수신신호의 상호 스펙트럼 밀도의 co-spectrum, quadrature spectrum으로부터 산출한 수평방향에 대한 전기적 인 위상각은 $46.4^{\circ}$ 이었고, 이 값에 대한 기계적인 위상각, 즉, 음축에 대한 transponder의 위치각은 약 $7.4^{\circ}$ 이었다. 이 결과로 부터 transponder의 수평방향에 대한 추정 위치각은 실제의 위 치각과 $+0.3^{\circ}$, 수직방향의 추정 위치각은 $-0.3^{\circ}$ 의 오차를 나타 내어 본 연구에서 개발한 split beam 음향 변환기는 transponder의 위치 모니터링에도 효과적으로 사용할 수 있음을 알 수 있었다.

\section{사 사}

이 논문은 2009년도 정부(교육과학기술부)의 재원으로 한 국연구재단의 지원을 받아 수행된 기초연구사업임(No. 20090071881).

\section{참고문헌}

Balanis CA. 1997. Anetenna Theory. John Wiley \& Son Inc. New York, U.S.A., 294-306.

Brede R, Kristensen FH, Solli H and Ona E. 1987. Target tracking with a split beam echo sounder. Int Sym on Fish Acoustics 87, 1-16.

Foote KG. 1990. Designing an improved transducer array geometry. J Cons int Explor Mer 46, 129-132.

Hans VS and Francis WZ. 2001. Statistical analysis in climate research. Cambridge University Press, London, U.K., 235236.

Hood CJ. 1987. Measurements of a split beam transducer. Int.
Sym on Fish. Acoustics 87, 1-23.

Lee DJ. 1999. Instrument engineering for fishing. Tae Hwa Publishing, Busan, Korea, 198-200.

Lee DJ and Lee WS. 2010. Design, fabrication and performance characteristics of a $50 \mathrm{kHz}$ tonpilz type transducer with a half-wavelength diameter. J Kor Soc Fish Tech 46, 173183.

Lee DJ and Lee WS. 2011. Development of 50kHz split-beam acoustic transducer for a fish sizing echo sounder. Kor J Fish Aquat Sci 44, 44-53.

MacLeannan DN, Simmonds EJ. 1995. Fisheries Acoustics. Chaman \& Hall, London. U.K., 45-88

Malcolm JC. 1998. Handbook of acoustics. John Wiley \& Sons Inc., New York, U.S.A., 1058-1059.

Martyna M and Thomas B. 2010. Real Wages and the Business Cycle in Germany. IZA DP No 5199, 17-20.

Park HY, Kim MJ, Lee DJ, Yoon JR and Kim CD. 2004. Splitbeam method for fish finder using a band-limited sweep. Proceeding of ICA 2004, 759-760.

Quaji AH. 1982. Array beam response in the presence of amplitude and phase fluctuations. J Acoust Soc Am 72 (1), 171-180.

Ziomeck LJ. 1985. Underwater Acoustics. Academic Press, Inc., New York, U.S.A., 94-152.

2011년 4월 12일 접수

2011년 5월 11일 수정

2011년 7월 27일 수리 